obtained for the atomic weight of dysprosium. This value is considerably higher than the one now in the International Table.

5. Some properties of dysprosium chloride are given.

6. The specific gravity of dysprosium oxide was found to be $7.8 \mathrm{I}$.

[CONTRIBUtion From THE DEPARTMENT OF PEDiatrics, the JoHNS Hopkins HOSPITAL.]

\title{
A COLORIMETRIC METHOD FOR THE DETERMINATION OF THE $\mathrm{CO}_{2}$ PERCENTAGE IN AIR.
}

By H. I. HIGgins and W. McKiM Marriotr. Received October 30, 1916.

An analysis for $\mathrm{CO}_{2}$ in the air is the simplest and probably the most used method of determining the condition of the ventilation in halls, school-rooms, factories, mines, submarines, etc. This method would doubtless be still more extensively used if it were not that a more or less expensive apparatus and a fairly skilful analyst are required. One of us has recently described a simple method for determining the carbon dioxide tension in the alveolar air. ${ }^{2}$ With some slight modification this same method may be applied for the determination of $\mathrm{CO}_{2}$ of any percentage in air.

Principle of the Method of Analysis.-If a current of air containing $\mathrm{CO}_{2}$ is passed through a solution of sodium bicarbonate until the solution is saturated with $\mathrm{CO}_{2}$, the final solution will contain sodium bicarbonate and dissolved $\mathrm{CO}_{2}$. The reaction (hydrogen-ion concentration) of such a solution will depend on the relative amounts of the alkaline bicarbonate and the carbonic acid present. This, in turn, will depend on the pressure of the carbon dioxide in the air with which the mixture has been saturated and will be independent of the volume of air blown through, provided saturation has once been attained. High pressures of carbon dioxide change the reaction of the solution toward the acid side. Low pressures have the reverse effect; hence the reaction of such a solution is a measure of the pressure of $\mathrm{CO}_{2}$ in the air with which it has been saturated.

The reaction of such a solution may be determined by adding to it an indicator such as phenolsulfonephthalein ${ }^{2}$ which shows over a considerable range of reaction definite color changes, and by comparing the resulting color with solutions of a known reaction containing the same amount of indicator.

Solutions of a given reaction may be prepared by mixing acid and alkaline phosphates in definite proportions. Such solutions, owing to

1 Marriott, J. Am. Med. Assoc., 66, I594 (1916).

2 Levy, R. L., Rowntree, I. G. and Marriott, W. M., "A Simple Method for Determining Variations in the Hydrogen-Ion Concentration of the Blood," Arck. Int. Med., 16, 389 (1915). 
their high "buffer" value, may be kept unaltered for long periods of time and can be used as standards for comparison.

Apparatus Required.-The apparatus required consists of ten small test tubes containing phosphate indicator solutions, an atomizer bulb, an ordinary glass tube drawn out to a point, and standard bicarbonate solutions. A small colorimeter box is desirable but not essential.

Preparation of Standard Phosphate Solutions. Fifteenth molecular Acid Potassium Phosphate.-Of the 'pure, recrystallized salt $\left(\mathrm{KH}_{2} \mathrm{PO}_{4}\right)$, $9.078 \mathrm{~g}$. are dissolved in distilled water, $200 \mathrm{cc}$. of $0.0 \mathrm{\%} \%$ phenolsulfonephthalein ${ }^{1}$ solution are added, and the whole is made up to I liter.

Fifteenth Molecular Alkaline Sodium Phosphate.-The pure, recrystallized salt $\left(\mathrm{Na}_{2} \mathrm{HPO}_{4} \cdot \mathrm{I}_{2} \mathrm{H}_{2} \mathrm{O}\right)$ is exposed to the air for from ten days to two weeks, protected from dust. Ten molecules of water of crystallization are given off and a salt of the formula $\mathrm{Na}_{2} \mathrm{HPO}_{4} \cdot 2 \mathrm{H}_{2} \mathrm{O}$ is obtained. Of this salt, I I.876 g. are dissolved in water, $200 \mathrm{cc}$. of $0.0 \mathrm{r} \%$ phenolsulfonephthalein solution are added, and the whole is made up to I liter. The solutions are mixed in the proportions indicated in the tabulation.

PROportions in which SOLUtions ARE Mixed.

$\begin{array}{lllllllllll}\text { Tube marked. } & 3 . & 7 . & 10 . & 15 . & 20 . & 25 . & 30 . & 40 . & 50 . & 60 .\end{array}$

Acid potassium phosphate, cc.... 5.4 I0.5 I5.0 $20.0 \quad 25.0 \quad 29.0 \quad 33.0 \quad 40.5 \quad 46.5 \quad 52.0$ Alkaline sodium phosphate, cc.... $94.6 \quad 89.5 \quad 85.0 \quad 80.0 \quad 75.0 \quad 71.0 \quad 67.0 \quad 59.5 \quad 53.5 \quad 48.0$

The solutions thus made are put in small test tubes (a convenient size is Io by $75 \mathrm{~mm}$.) and stoppered and sealed off. These standard tubes should be kept in a dark place when not in use.

Two standard bicarbonate solutions have been used by us. Solution "A" is o.0or $N$ and may be made by taking ro cc. of o. I $N$ NaOH or $\mathrm{Na}_{2} \mathrm{CO}_{3}$, adding $200 \mathrm{cc}$. of $0.01 \%$ phenolsulfonephthalein and making up to rooo cc. Solution "B" is $0.0085 N$ and may be made by taking 85 cc. of o. I N NaOH or $\mathrm{Na}_{2} \mathrm{CO}_{3}$, adding $200 \mathrm{cc}$. of $0.01 \%$ phenolsulfonephthalein and making up to $1000 \mathrm{cc}$. $\mathrm{CO}_{2}$ from a cylinder or from the lungs may be passed through these solutions to convert the alkali into bicarbonate.

The standard phosphate solutions used were made of the same strengths as those used by Sörensen. ${ }^{2}$ The proportions in which the solutions were mixed were determined empirically: Air was analyzed to determine its $\mathrm{CO}_{2}$ content, and then passed through the sodium bicarbonate indicator solution; a mixture was then made of the phosphate solutions to give the same color.

1 Biologically standardized phenolsulfonephthalein, on the market for renal functional tests, is not suitable as it contains sodium bicarbonate. The pure dye in solution may be obtained of Hynson, Westcott and Dunning, Baltimore; this firm will also furnish the standard phosphate tubes and sodium bicarbonate solutions containing the indicator and the complete apparatus as described here.

2 Sörensen, Biochem. Z., 22, 352 (1909). 
All of the standard solutions used in this method must be kept in glass which does not readily give off alkali, that is to say such glass as "Jena," "Non-sol" or "Pyrex." A small amount of thymol or toluol added to each solution serves to prevent the growth of molds.

Technique of the Method of Analysis.-In analyzing a sample of air, about 2 or $3 \mathrm{cc}$. of one of the standard bicarbonate solutions are poured into a clean test tube of the same diameter as the tubes containing standard phosphate solutions, but from 100 to $150 \mathrm{~mm}$. long. ${ }^{1}$ Air is then blown from the room by means of an atomizer bulb and a glass tube drawn out to a fine point until the solution is saturated, as shown by the fact that no further color change occurs. This usually requires not over one minute. The tube is stoppered with a paraffined cork and the color immediately compared with that in the standard tubes. Percentages of $\mathrm{CO}_{2}$ are read off directly. The standard solutions are so prepared that the figures represent parts of $\mathrm{CO}_{2}$ in ten thousand or hundredths of one per cent. when compared with bicarbonate Solution " $A$ " saturated with the air sample. When Solution "B" is used instead, the numbers on the tubes represent parts of $\mathrm{CO}_{2}$ in $\mathrm{I}$ (OoO or tenths of $\mathrm{I} \%$. For example, if Solution "A," when saturated with the air to be analyzed has the same color as the standard tube marked " 7 ," the air contains seven parts of $\mathrm{CO}_{2}$ in ten thousand or $0.07 \%$. If, on the other hand, Solution " $B$ " should take on the same color as tube " 7 " it would mean that the air contained seven parts of $\mathrm{CO}_{2}$ in a thousand or $0.7 \% .^{2}$

The comparison with the standard colors is conveniently made with a box similar to that used with the Sahli hemoglobinometer, but containing three instead of two holes. It is a small, flat box of blackened metal, 55 by 45 by $20 \mathrm{~mm}$., backed with opal glass and with three slits open on the front. By the use of this device, slight color changes may be easily detected, and the temperature of the tubes is not raised by the heat of the hands. In making the color comparisons, the solution being compared is placed between the two standards which it most nearly matches. When there is doubt as to whether the color of the solution is higher or lower than one of the standards, changing the order in which the tubes are placed in the comparison box will generally make the relationships clear. By interpolation, one can read quite accurately. The accuracy to which we

1 The bicarbonate need not be renewed for each analysis. The same selution will serve for several determinations.

2 For analysis of $\mathrm{CO}_{2}$ higher than $6 \%$, a stronger bicarbonate solution will be required. By comparison of the color produced by $\mathrm{CO}_{2}$ percentages, which have been determined by gas analysis, with the standard tubes, one can find the percentage value of each of the phosphate solutions for the bicarbonate solution taken. In our standardization, we have found a basket-ball bladder very handy for making and holding the gases of the higher $\mathrm{CO}_{2}$ percentages; one could blow the air through the bicarbonate solutions from the bag, and also obtain a sample for a gas analysis. 
have been able to use this method is to about $5 \%$ of the total figure; that is to $0.005 \%$ when the reading is $0.10 \% \mathrm{CO}_{2}$ and to $0.20 \%$ when the reading is $4 \% \mathrm{CO}_{2}$.

The above solutions were standardized for temperatures of $20^{\circ}$ to $25^{\circ}$. If the temperature is higher, the percentages as read are too low; if the temperature is lower, the percentages are too high. A temperature of $15^{\circ}$ gave readings about $10 \%$ too high and one of $30^{\circ}, 10 \%$ too low. This difficulty may be obviated by immersing the tubes in water at $20-25^{\circ}$, and blowing the air through the bicarbonate solution thus immersed. Changes in humidity do not affect the readings.

As the color of the standard bicarbonate solutions varies according to the carbon dioxide pressure of the air passing through it, in places where the barometer reads higher than $800 \mathrm{~mm}$. or lower than $730 \mathrm{~mm}$. a correction must be applied to the percentages given on the standard tubes. Variations of the barometer from day to day are negligible. The corrected percentage would be $\frac{\text { barometer }}{760} \times \% \mathrm{CO}_{2}$ read.

The method is not applicable in the presence of acid or ammonia fumes. As outdoor air always contains practically the same percentage $(0.03 \%)$ of $\mathrm{CO}_{2}$, the bicarbonate solution " $\mathrm{A}$ " may be easily checked.

BALTIMORE, MD.

[CONTRIBUTION FROM THE SCHOOL OF ChEMISTRY, UNIVERSITY OF PITTSBURGh.]

STUDIES IN DIALYSIS.

\section{THE HOT DIALYSIS OF THE CHLORIDES OF FERRIC IRON, CHRO- MIUM AND ALUMINIUM, AND THE RAPID PREPARATION OF THEIR COLLOTDAL HYDROUS OXIDES.}

By MaRzs NeIdLE and Jacob Barab.

Received November 13, 1916.

The primary object of the present research was the application of the method of hot dialysis ${ }^{1}$ to the rapid preparation of the colloidal hydrous oxides of ferric iron, chromium and aluminium. Incidentally we have studied the "cold dialysis" of the chlorides of these three metals, with continuous changing of diffusate, and contrasted our results with those of previous investigators. An attempt has also been made, as far as possible, to standardize the methods employed by furnishing sufficient details to enable others to approximately reproduce our results.

In general, when one wishes to prepare a hydrosol fairly free from electrolytes by the usual method of dialysis, it is necessary to dialyze for about thirty days. Some investigators have permitted their dialyses to extend for greater periods, in several cases as long as six months. ${ }^{2}$

${ }^{1}$ Neidle, This Journal, 38, 1270 (1916).

2 Pappada, Z. Ind. Chem. Koll., 9, 233 (I9II). 